\title{
Trivium
}

Revue franco-allemande de sciences humaines et sociales - Deutsch-französische Zeitschrift für Geistesund Sozialwissenschaften

29 | 2019

Regards croisés sur le prophète de l'Islam

\section{Der Körper des Propheten}

\section{Denis Gril}

Traducteur : Bettina Engels et Nikolaus Gramm

\section{(2) OpenEdition}

\section{Journals}

Édition électronique

URL : http://journals.openedition.org/trivium/6268

DOI : $10.4000 /$ trivium.6268

ISBN : 1963-1820

ISSN : 1963-1820

\section{Éditeur}

Les éditions de la Maison des sciences de l'Homme

\section{Référence électronique}

Denis Gril, « Der Körper des Propheten », Trivium [Online], 29 | 2019, online erschienen am 17 Oktober 2019, abgerufen am 08 September 2020. URL : http://journals.openedition.org/trivium/6268 ; DOI : https://doi.org/10.4000/trivium.6268

\section{Ce document a été généré automatiquement le 8 septembre 2020}

\section{(c) (i) (9)}

Les contenus des la revue Trivium sont mis à disposition selon les termes de la Licence Creative Commons Attribution - Pas d'Utilisation Commerciale - Pas de Modification 4.0 International. 


\title{
Der Körper des Propheten
}

\author{
Denis Gril \\ Traduction : Bettina Engels et Nikolaus Gramm
}

\section{NOTE DE L'ÉDITEUR}

Wir danken Herrn Denis Gril für die freundliche Genehmigung, diesen Artikel in deutscher Übersetzung zu publizieren.

Nous remercions M. Denis Gril de nous avoir accordé l'autorisation de traduire ce texte pour le présent numéro.

1 Die Beziehung des Körpers zum Heiligen ist eine doppelte: Der Körper ist vom Heiligen gezeichnet und spiegelt dessen Gegenwart wider. Wenn man es als das definiert, was im Gegensatz zur gewöhnlichen oder profanen Welt - die Spur des Göttlichen trägt, so hat das Heilige im Islam seine Quelle vor allem in der Offenbarung, einer transzendenten Realität, die dem Koran zufolge auf das Herz des Propheten herabgekommen ist. ${ }^{1}$ Zugleich Empfänger und Übermittler des heiligen und heiligenden Wortes, ist der Prophet daher primär an der Stiftung von Sakralität beteiligt. Diese gesetzgeberische Rolle der Propheten lässt sich am Beispiel Abrahams illustrieren, der zu Gott betet und die Stadt Mekka und ihre Umgebung zu heiligem ( harâm) Territorium erklärt. ${ }^{2}$ Der Prophet verfügt im Gefolge seines Stammvaters dasselbe für Medina. ${ }^{3}$ Die Sakralisierung eines Ortes, einer Sache oder eines Lebewesens macht sie unverletzlich und belegt sie mit gewissen Verboten. Mit der Aufstellung des Gesetzes wird der Gegensatz heilig / profan durch den Gegensatz verboten / erlaubt ( ḩarâm / halâl) ergänzt, der mit seinen Unterkategorien Dinge, Personen und Taten qualifiziert. Da alles vom göttlichen, offenbarten oder kosmischen Gesetz bestimmt ist, kann sich, einer bestimmten Sichtweise zufolge, nichts der Kategorie des Heiligen entziehen. Nach der Sunna ist die Erdoberfläche, die dem Propheten und seiner Gemeinschaft als Ort der Läuterung und des Sichniederwerfens gegeben ist, ${ }^{4}$ zur Gänze heilig, mit Ausnahme bestimmter, durch menschlichen oder tierischen Gebrauch beschmutzter Orte, an denen das Gebet verboten ist. Ebenso ist jeder Mensch für seinen 
Nächsten heilig, wie der Prophet auf seiner Abschiedswallfahrt, die Hauptgebote des Gesetzes zusammenfassend, noch einmal feierlich erklärt. ${ }^{5}$ Alle Wesen und Dinge haben daher zu verschiedenen Graden am Heiligen teil, und ihr profaner Charakter ist nur Ausdruck davon, dass ihnen ein spezifischer Status der Heiligkeit fehlt. Für die Menschen gilt, dass ihr mehr oder minder enger Kontakt zum Sakralen ihrer Person und insbesondere ihrem Körper ein größeres oder kleineres Maß an Heiligkeit (sacralité ) verleiht. Sie ist entweder mit einem Amt - z. B. dem Priesteramt - verbunden oder mit einer inneren Nähe zum Göttlichen, die zwar als solche nicht wahrnehmbar ist, doch an bestimmten - mitunter körperlichen - Zeichen abgelesen werden kann. Das, was man im Allgemeinen als Heiligkeit (sainteté) bezeichnet, und die Erforschung ihrer Erscheinungsformen haben das Interesse der Organisatoren dieses Kolloquiums an Ort und Funktion des Körpers sowohl in der hagiographischen Literatur als auch in den Praktiken der Spiritualität und der Heiligen-»Verehrung« geweckt.

Über die Bedeutung des Körpers und seine Bewertung im heiligen Gesetz des Islam, ebenso wie in den Riten und den zahlreichen von diesem Gesetz vorgeschriebenen Lebensregeln, gibt es viel zu sagen. In den verschiedenen Initiationsmethoden des Sufismus spielt der Körper eine nicht minder große Rolle, und die innere Verehrung, die den spirituellen Meistern und den Heiligen im Allgemeinen zuteil wird, erstreckt sich auch auf ihren Körper. Die in unseren Untersuchungen gelegentlich berührte Frage hätte eigentlich eine eigene Forschungsarbeit verdient.

Im vorliegenden Aufsatz soll nun gezeigt werden, dass die Verehrung der Körper der Heiligen und die Erwähnung ihrer körperlichen Eigenschaften größtenteils dem Modell des von seinen Gefährten verehrten und beschriebenen Propheten folgt. ${ }^{6}$ Seine Nähe zu Gott und die Herabsendung von Gottes Wort auf ihn machen ihn zum Heiligsten unter den Menschen und seinen Körper zum heiligsten aller Körper. Dem Kontakt mit ihm wird allergrößter Respekt gezollt, und er wird sogar als Wegzehrung für das Jenseits betrachtet. Die Wiederaufnahme dieses Modells in der hagiographischen Literatur oder in den Anstandsregeln (âdâb) für die Beziehungen zwischen Meister und Schüler könnten das Thema einer weiteren Studie sein.

Der Koran spricht nicht vom Körper des Propheten, sondern allein von seinem Herzen, dem Ort der herabgesandten Offenbarung. Es wird einfach nur daran erinnert, dass die Heiligen essen, trinken und auf Märkte gehen wie alle anderen Menschen, um ihr von den Engeln verschiedenes menschliches Wesen zu betonen (Koran 21:8, 23:33, 25:20). Die Sunna dagegen beinhaltet zahlreiche Berichte über die körperliche Erscheinung Muhammads und die seinem Körper gezollten Ehrerbietungen. Den Überlieferern und Kompilatoren solcher Informationen war also bewusst, dass die unabdingbare Beziehung zwischen dem - mit der Welt Gottes und der Engel in Kontakt stehenden Herzen dieses Menschen und seinem Körper Letzteren heiligte. Die Verbindung zwischen der äußeren Erscheinung und der inneren Form, zwischen khalq und khulq, wird in der Sunna als offenkundige Tatsache dargestellt - ganz gleich, ob es um den Propheten oder einen beliebigen Menschen geht. Die die Genesis aufgreifende Überlieferung, der zufolge Adam nach dem Bild oder der Form Gottes geschaffen wurde (Bukhârî 2001, [isti'dhân] 1, Nr.6228), stellt die Frage nach den subtilen und geheimnisvollen Beziehungen zwischen Körper und Seele bzw. Geist. Die griechischen und später die islamischen Philosophen haben sich lange mit dieser Frage befasst. ${ }^{7}$

5 Die arabische Sprache kennt drei verschiedene Wörter für den Körper und spiegelt so die Komplexität der Beziehung zwischen Körper und Geist wider. Im Koran bezeichnet 
jism (Pl. ajsâm) den Körper im Allgemeinen, den körperlichen Aspekt des Menschen, in Entsprechung oder in Gegensatz zu seiner inneren Dimension. Um das Königtum Sauls zu rechtfertigen, erklärt der Prophet (Samuel) den Söhnen Israels: „Gott hat ihn aus euch Erwählt und ihm GrößE an Wissen und Gestalt verliehen (zâda-hu basțat ${ }^{a n}$ fî l-ilm wa l-jism)« (Koran 2:247), und Gott sagt dem Propheten hinsichtlich der Heuchler: „WEnn du siE siehst, gefallen dir ihrE GEstaltEn« (ebd. 63:4). Jasad bezeichnet dagegen die körperliche Form, die ein Geist angenommen hat, um den Menschen zu erscheinen. Wie bereits angedeutet, wird dieser Ausdruck auf die Propheten angewandt, um sie von Engeln zu unterscheiden: „Wir machten sie nicht zu Körpern, die nicht essen, und sie warEn nicht Ewig" (ebd. 21:8). Um Salomo auf die Probe zu stellen und ihm die gänzliche Abhängigkeit seiner Königlichkeit vor Augen zu führen, installiert Gott - so eine der Interpretationen dieses Verses - einen Dämon auf Salomos Thron, der vierzig Tage lang an dessen Stelle regiert: »Wir prüften Salomo und sEtztEn auf sEinEn Thron EinE GEstalt. Dann kehrte er reumütig um« (ebd. 38:34). In ähnlichem Sinne wird das Goldene Kalb jasad genannt, denn die Statue wurde durch ein paar Spritzer jenes Schlicks beseelt, auf dem Gabriels Pferd bei der Durchquerung des Roten Meers einen Hufabdruck hinterlassen hatte und der dann von Sâmirî aufgesammelt wurde. ${ }^{8}$ Der Begriff badan dagegen wird nur ein einziges Mal verwendet, als der Körper des Pharaos von den Fluten verschont wird, denn mit diesem Wort wird, den Exegeten zufolge, »ein Körper ohne Geist « (jasad lâ rûha fîhi) bezeichnet. ${ }^{9}$ Ein Geist kann also in einen Körper hinabsteigen, so wenn Gabriel dem Propheten oder den Gefährten - ohne aber von ihnen erkannt zu werden - in Menschengestalt erscheint. ${ }^{10}$ Man spricht dann von der "Körperwerdung " (corporisation) der Geister (tajassud al-arwâh). Im Falle des Engels oder niederen Geistes löst sich diese körperliche Form auf, wenn der Geist sie verlässt, während der verstorbene Mensch als lebloser Körper zurückbleibt. Die genaue Verwendung dieser drei Begriffe im Koran entspricht nicht unbedingt ihrem weitgehend austauschbaren Gebrauch im klassischen Arabisch, wenn man dem Lisân al-'Arab, dem großen Wörterbuch des Ibn Manzûr (gest. 711/1311) Glauben schenkt. ${ }^{11}$ Im Hadith bestätigen die Fundstellen von jasad - das weit häufiger als das sehr wenig bezeugte jism vorkommt - diese Auffassung des Körpers in seiner Beziehung zum Geist. 12

\section{Der Körper des Erwählten}

6 Der Körper des Siegels der Propheten, des Erwählten unter den Erwählten, kann nur ein außergewöhnlicher Körper sein, denn er ist dazu bestimmt, das Wort Gottes aufzunehmen. Bereits vor seiner Geburt, bei seiner Zeugung, nach oder während seiner Ankunft auf der Welt begleitet ein sichtbares Zeichen seinen ersten irdischen Auftritt. Seine Mutter sieht in der Schwangerschaft ein Licht aus sich hervortreten, das die Schlösser von Bosra in Syrien erleuchtet (Ibn Hishâm 2017 [1884], 63). Dieses Licht, das nach der Sîra von ihrem Vater 'Abdallâh auf ihre Mutter Amîna überging (ebd., S. 62 f.), stellt das In-die-Welt-Herabsteigen des Körpers des prophetischen Geistes dar. ${ }^{13}$ Der Bericht von der Kindheit des Propheten hebt sein rasches Wachstum während des Aufenthaltes bei seiner Amme Ḥalîma al-Sa'diyya hervor. Dort wird sein Körper einer Operation unterzogen, die der Reinigung seines inneren Seins dient. Laut seinem Milchbruder, mit dem er die Schafe hütet, bringen zwei weißgekleidete Männer ihn in ihre Gewalt, öffnen ihm das Herz, entfernen daraus ein schwarzes Blutgerinnsel und 
waschen Herz und Eingeweide mit Schnee. Diese Episode muss man zu den Worten in Beziehung setzen, die die Mutter Marias bei der Geburt ihrer Tochter an Gott richtet: »Ich habE Es [das Kind] Maria gEnannt und stelle es mit ihren Nachkommen unter deinen Schutz vor dem gesteinigten Satan." (Koran 3:36). Gemäß der exegetischen Tradition wurden nur Maria und Jesus vor der Berührung Satans geschützt, der die Kinder bei ihrer Geburt weinen lässt (Ṭabarî, A. 1971, Bd. 6, S. 336-343). Dieser Schutz hat Maria zum vollkommenen Gefäß des Gottesworts und ihren Sohn zu dessen offenbarer Inkarnation gemacht. Muhammad, der im Gegensatz zu Jesus nicht als Prophet geboren wird, verkörpert eine scheinbar gewöhnliche Menschlichkeit, um mittels dieser das Werk Gottes - hier: der Reinigung - zu offenbaren. Die Menschen müssen auch seinem - körperlichen und geistigen - Vorbild folgen; das bezeugt der göttliche Schutz, um den er auch während der Koranlektüre noch bitten muss. ${ }^{14}$ Vor der Nachtreise und der Himmelfahrt - einem Ereignis, das in umgekehrter Spiegelbildlichkeit zur Herabkunft des Wortes steht und das Auserwähltsein des Propheten besiegelt - wird sein Herz ein zweites Mal geöffnet, gewaschen und vom Glauben erfüllt, um ihn auf die Schau der höchsten Zeichen vorzubereiten $\cdot{ }^{15}$ Es geht ein weiteres Mal darum, den Körper auf ein sicherlich spirituelles, doch die Gesamtheit seines Seins betreffendes Ereignis vorzubereiten. Tatsächlich reist Muhammad mit seinem Körper ${ }^{16}$ von Mekka nach Jerusalem, um von dort aus durch die Himmel zu seinem Herrn aufzufahren.

7 Die Vorbereitung von Herz und Körper erklärt sich aus der für die Aufnahme des Wortes und die Auffahrt zu Gott erforderlichen Reinheit, aber auch aus dem belastenden Charakter der Offenbarung. Der Bericht von Muhammads erster Engelserscheinung betont deren physische Auswirkungen: die dreifache Umarmung des Engels, die den Propheten beinahe ersticken lässt, bevor er die ersten Verse des Korans wiederzugeben vermag, ebenso wie das Beben, das anschließend seinen Körper ergreift (Bukhârî 2001: Vom Beginn der Offenbarung (bad' al-wahy) 1, Nr. 1-4). Diese körperlichen Reaktionen begleiten seine gesamte Mission. 'Â'isha berichtet, sie habe an einem sehr kalten Tag den Schweiß auf seiner Stirn herabrinnen gesehen. Im Sitzen, seinen Oberschenkel auf dem Schenkel eines Gefährten abgestützt, beginnt der Prophet, die Offenbarung zu empfangen. Dabei wird sein Schenkel so schwer, dass der Gefährte das Gefühl hat, der eigene werde ihm gleich brechen. ${ }^{17}$ Ebenso versagen die Vorderbeine der Kamelstute, die der Prophet reitet, als der Koran auf ihn herabkommt, ihren Dienst (Ibn Sa'd, o. J., Bd. 1, S. 197). Diese Details unterstreichen, wie sich die Wirkungen des an das Herz gerichteten Wortes bis in die körperliche Welt fortsetzen und damit denjenigen, der es empfängt, heiligen. Sein Körper trägt sogar das Zeichen seiner Mission: Zwischen seinen Schulterblättern findet sich »das Siegel des Prophetentums « (khâtam al-nubuwwa), eine Art Höcker aus Körpergewebe, das mit einem Taubenei, einem Apfel oder dem Abdruck eines Saugnapfes verglichen worden ist. Dank dieses körperlichen Zeichens wird er endgültig als der Prophet anerkannt, den gewisse in der Tradition der "Leute der Schrift" stehende Persönlichkeiten - wie der Mönch Bahîrâ, der seinen Onkel Abû Ṭâlib in Syrien begleitet, ${ }^{18}$ oder Salmân kurz vor seiner Ankunft in Medina - schon erwartet haben (Ibn Hishâm 1995, Bd. 1, S. 220). ${ }^{19}$ 


\section{Schleier und Heiligkeit}

8 Da er von Kind auf die körperlichen Zeichen seines Auserwähltseins trägt, da er wächst und - mehr als jeder andere Mensch - dem Blick Gottes ausgesetzt ist, kann Muhammad nicht dieselbe Beziehung zu seinem Körper pflegen wie ein gewöhnlicher Mensch. Die Nacktheit war bei den vorislamischen Arabern offensichtlich nicht mit einem Verbot belegt..$^{20}$ Als er mit anderen Kindern Steine schleppt, legt der zukünftige Prophet genau wie die anderen seinen Lendenschurz ab, um damit seine Schulter zu schützen. Gleichsam aus dem Nichts erhält er eine Ohrfeige und vernimmt den Befehl, seinen Lendenschurz wieder anzulegen. Als junger Mann beteiligt er sich später am Wiederaufbau der Ka'ba. Sein Onkel al-'Abbâs rät ihm, es wie alle Welt zu halten und den Lendenschurz zum Steinetragen zu verwenden. Er gehorcht schließlich, fällt aber alsbald in Ohnmacht und bedeckt seine Blöße (Ibn Hishâm 1955, Bd. 1, S. 183).

In seinem Eheleben zeigt er sich niemals nackt und richtet seinen Blick nie auf die Geschlechtsteile seiner Ehefrauen, ${ }^{21}$ obwohl ein solcher Blick unter Eheleuten erlaubt ist. Dies tut er nicht allein aus Scham, sondern auch um die Heiligkeit des Körpers zu bewahren, der nicht gesehen werden darf und auch nicht sehen darf, was einen Schleier zwischen den Propheten und die Schau der heiligen Dinge legen könnte. Obwohl die Sexualität im Islam zutiefst vom Sakralen geprägt ist, baut der sexuelle Kontakt doch normalerweise mindestens eine Distanz zur Gegenwart Gottes und der Engel auf. Als der Prophet nach der ersten Erscheinung Gabriels an der Natur des Wesens zweifelt, das sich ihm gezeigt hat, bittet ihn seine Frau Khadîja, sie im Falle einer erneuten Erscheinung zu verständigen, und er leistet ihrer Bitte Folge. Nach einer Version dieser Anekdote nimmt sie ihren Schleier ab, nach einer anderen Version schmiegt sie sich unter seiner Tunika an den Körper des Propheten. Der Engel, der sich einem Mann in so inniger Verbindung zu seiner Frau nicht nähern darf, entfernt sich; Muhammad ist daraufhin beruhigt und hat nun die Gewissheit, keinem Dämon aufgesessen zu sein (Ibn Hishâm 1955, Bd. 1, S. 239). Der Körper in seiner ambivalenten Beziehung zum Sakralen findet sich hier an der Grenze zweier Intimitäten, die gleichermaßen heilig sind, sich aber wechselseitig ausschließen. Für den unmittelbaren Kontakt zu Gott oder seinem Boten müssen Mann und Frau getrennt bleiben - von jeder Beziehung zum anderen gereinigt, wie die Verbote im Kontext der Gebetsriten, des Fastens, der Pilgerreise oder der sexuellen Beziehungen zeigen -, um die Reinheit des Herzens zu bewahren und die familiären und gesellschaftlichen Beziehungen zu schützen.

\section{Ein außergewöhnlicher Körper}

Die Beziehung des Propheten zu seinen Ehefrauen dient den Gläubigen beiderlei Geschlechts als Vorbild und veranschaulicht ein anderes Modell der Teilhabe des Körpers am Sakralen, das die eheliche Vereinigung und die Körperpflege würdigt. Hier müssen wir lediglich den Hadith zitieren: »Aus eurer Welt sind mir die Parfüme und die Frauen lieb geworden, und die >Frische meines Auges` wurde mir beim Gebet zuteil. « ${ }^{22}$ Auf diesem Gebiet erscheint der Körper des Propheten, genau wie auf anderen, ganz außergewöhnlich. Einer Überlieferung zufolge hatte er die sexuelle Potenz von vierzig Männern (Ibn Sa'd, o. J., Bd. 1, S. 374) und beglückte in einer Nacht alle seine Frauen. Ein einziges Mal und allein für die Zwecke seiner Mission demonstriert er 
außergewöhnliche Körperkraft: In Mekka begegnet er Rukâna, einem im Ringkampf als unbezwingbar geltenden Mann aus seinem Clan, und er fordert ihn auf, den Islam anzunehmen. Rukâna weigert sich. Der Prophet fragt ihn, ob er die Wahrheit seiner Botschaft anzuerkennen bereit sei, wenn es ihm gelänge, ihn im Kampf zu besiegen. Rukâna willigt ein. Zweimal streckt ihn der Prophet nieder. Daraufhin gibt er einem Baum ein Handzeichen, zu ihm zu kommen, und befiehlt ihm im Anschluss, an seinen Platz zurückzukehren. Von dieser Machtdemonstration ist der Ringer zwar beeindruckt, doch der Glaube durchdringt nicht sein Herz. Er kehrt zu den Seinigen zurück und sagt:

») ihr Söhne 'Abd Manâfs [Muhammad ist ein Nachfahre 'Abd Mânafs, A.d.Ü.], ihr könnt mit eurem Freunde allen Bewohner der Erde verzaubern, denn bei Gott, ich habe nie einen größeren Zauberer gesehen. Er erzählte ihnen dann [,] was Mohammed getan und was er selbst gesehen hatte.« (Ibn Hishâm 2017 [1884], S. 161)

Diese Art spektakulärer, doch wirkungsloser Großtaten, mit denen die Menschen zu Gott hingeführt werden sollen, ist im Leben des Propheten kaum bezeugt. Es sind andere Qualitäten - eine subtilere Wahrnehmung oder Aktion -, die sein wundersamer Körper im Allgemeinen zeigt. Eines Tages warnt er seine Gefährten:

»Ich bin euer Imam; geht vor mir weder geneigt noch kniefällig her und erhebt nicht das Haupt vor mir, denn ich sehe genauso gut vor wie hinter mir. Bei dem, der die Seele Muhammads in seiner Hand hält, wenn ihr sähet, was ich sehe, würdet ihr wenig lachen und viel weinen. Sie fragten: $\supset$ Gesandter Gottes, was hast du gesehen? «- ১Das Paradies und die Hölle`, antwortete er. «23

11 Das Sehvermögen des Propheten ist also weder durch den Raum noch durch die Grenze zwischen dieser und der anderen Welt beschränkt; sein Körper ist nicht mehr das Hindernis, das er für gewöhnliche Menschen ist, sondern folgt vielmehr seiner prophetischen Wahrnehmung.

Muhammad liebt nicht nur Parfums, sein Körper selbst verbreitet einen Moschusgeruch. Laut Jâbir bin 'Abdallâh konnte man ihm in Medina folgen, weil er im Vorübergehen einen Parfümgeruch hinterließ. Alle Ausscheidungen seines Körpers verströmten diesen Moschusgeruch: sein Speichel, sein Schweiß und selbst seine Exkremente, die nicht allein wohlriechend, sondern 'Â'ishas Bericht zufolge auch unsichtbar waren (Bayhaqî 1985, Bd. 6, S. 69 f.). ${ }^{24}$

Die Sîra oder der Hadith schreiben dem Propheten eine gewisse Zahl von Wundern zu, seien es Krankenheilungen oder Eingriffe zur Behebung von Schwierigkeiten. Sein Körper, insbesondere seine Hände, und die Emanationen seines Körpers wie Atem oder Speichel - oder beide zugleich - sind häufig das Hilfsmittel dieser Wunder. Oft bedient er sich seiner Hände. Er legt seine Hand mit gespreizten Fingern auf Fâțimas Hals, die Hunger leidet und ein äußerst blasses Gesicht hat, und ruft Gott an. Das Gesicht des Mädchens nimmt sogleich eine gesunde Farbe an, und sie beteuert, von diesem Moment an keinen Hunger mehr gekannt zu haben (Bayhaqî 1985, Bd. 6, S. 108). ${ }^{25} \mathrm{Er}$ legt seine Hand auf den Rand eines Brunnens, aus dem sogleich wieder Wasser hervorströmt (Ibn Hishâm 2017 [1884], S. 531), und mehrere Gefährten versichern, das Wasser aus seinen Fingern hervorsprudeln gesehen zu haben (Bayhaqî 1985, Bd. 6, S. 9-11, 62). Bei der Aushebung des Grabens in Medina widersetzt sich ein kompakter Felsblock der Hacke der Gefährten. Der Prophet spuckt in einen Behälter, spricht ein kurzes Gebet und gießt dann die Flüssigkeit über dem Felsen aus, der weich wird und keinerlei Widerstand mehr leistet (Ibn Hishâm 1955, S. 217 f.). Am Tag des Khaybar-Feldzugs übergibt er die 
Standarte an 'Alî, dessen Augen voller Augenschleim sind. Ihn anhauchend, spuckt (tafala) er auf die kranken Augen. 'Alî ist nicht nur geheilt, sondern von diesem Tag an mit übermenschlicher Kraft gesegnet; er kann alleine ein schweres Tor aus den Angeln heben und ermöglicht den Muslimen so die Einnahme der befestigten Stadt (Ibn Hishâm 1955, S. 334 f.). ${ }^{26}$ Der Prophet heilt eine zuvor unheilbare Wunde, indem er an seinem kleinen Finger leckt, mit diesem die Erde Medinas berührt und ihn dann über die Wunde gleiten lässt, wobei er folgende Beschwörungsformel spricht:

„Bei deinem Namen, o mein Gott, der Speichel von einem unter uns heilt zusammen mit dem Staub unserer Erde unseren Kranken, mit der Erlaubnis unseres Herrn.« (Bayhaqî 1985, Bd. 6, S. 170)

So lehrt er seine Gemeinschaft, sein Heilvermögen und die Heilwirkung der geheiligten Erde Medinas zu entdecken.

Die Wundertätigkeit des Prophetenkörpers, die sich auf viele Heilige übertragen wird, geht - wie wir sehen werden - mit einer an diesen Körper geknüpften eschatologischen Hoffnung einher. Es ist normal, dass ein vom Wort Gottes durchströmter Körper von dessen Regenerations- und Heilkraft durchdrungen ist. ${ }^{27}$ Allerdings erklärt sich das Interesse, das die Gefährten und die dann folgenden Generationen von Muslimen der physischen Erscheinung des Propheten und seinem Charakter entgegengebracht haben, gleichermaßen aus der Vorstellung, dass jeder dieser Züge - gemäß den Gesetzen des Physiognomie ${ }^{28}$ - von Bedeutung sein kann und dass der Eindruck von Harmonie und Gleichgewicht, der von seiner Person ausgeht, seine physische und zugleich spirituelle Vollkommenheit widerspiegelt. Sein junger Diener Anas bin Mâlik beschreibt ihn folgendermaßen:

»Er hatte unter den Leuten eine durchschnittliche Körpergröße; er war weder groß noch klein, hatte eine gesunde, schöne und durchblutete Hautfarbe, die weder auffallend hellweiß noch dunkel war. Sein Haar war weder kurz und krausig noch glattfallend noch sehr lang. Auf ihn wurde die Botschaft herabgesandt, als er vierzig Jahre alt wurde. Er verbrachte in Makka zehn Jahre, in deren Verlauf die Offenbarung zu ihm kam. In Al-Madîna verbrachte er noch zehn Jahre; und als er starb, waren auf seinem Kopf und in seinem Bart zusammen nicht einmal zwanzig weiße Haare« (Bukhârî 2015, manâqib 3547, S. 375).

In diesem kurzen Text leitet die Beschreibung des physischen Erscheinungsbildes die Erinnerung an die beiden Phasen seiner prophetischen Karriere ein und schließt sie auch wieder ab - was zeigt, dass für den Gefährten, der diesen Text verfasste und den Propheten aus der Nähe kannte, beides in engstem Zusammenhang steht. Alle HadithSammlungen enthalten ein Kapitel mit Beschreibungen des Propheten (șifât al-nabî). Die Schilderung seiner körperlichen Erscheinung brachte sogar eine Art Vulgata hervor, den Hadith 'Alîs, in dem der Prophet sehr genau beschrieben wird:

»Er war weder übermäßig groß noch klein und stämmig, sondern von mittlerer Größe. Sein Haar war weder besonders kraus noch glatt, sondern lang und gewellt. Sein Gesicht war nicht zu groß, seine Wangen nicht zu rund. Seine Haut war weiß mit einem rosigen Teint. Seine Augen waren tiefschwarz, seine Wimpern waren lang. Seine Gliedmaßen und seine Schultern waren kräftig. Seine Brust war stark behaart, seine Hände und Füße aber weniger. Er ging mit schnellen Schritten, als ob er einen Hang hinabliefe. Wenn er sich umdrehte, wandte er seinen ganzen Körper herum. Er, der das Siegel der Propheten war, trug zwischen den Schultern das Siegel des Prophetentums. Niemand gab freigiebiger als er, niemand hatte eine offenere Brust. Er war der wahrheitsliebendste der Menschen, hielt seine Versprechungen mit größter Treue, hatte den mildesten Charakter und war in Gesellschaft äußerst entgegenkommend. Wer ihn zum ersten Mal sah, verspürte respektvolle Furcht; wer häufig mit ihm zusammenkam, liebte ihn. Der Autor dieser 
Beschreibung fügte noch hinzu: >Niemals habe ich vorher oder nachher jemanden wie ihn gesehen - Gott möge ihm Gnade und Frieden gewähren.« (Ibn Hishâm 1955, Bd. 1, S. 401 f.). ${ }^{29}$

Diese Überlieferung ist sogar ein kalligraphisches Motiv geworden: Der Text wurde in der Regel in einen illuminierten, Hilya (Schmuck, Zierde) genannten Rahmen eingeschrieben. ${ }^{30}$ Symbolisch betrachtet wird der Körper wenn nicht zum Wort, so doch zur Schrift, was nahelegt, dass er, vom göttlichen Wort und dessen Bedeutung erfüllt, zum Buch wird - so wie vom Propheten gesagt wird, dass »er ein auf der Erde wandelnder Koran war «.

Diese Beschreibungen beschränken sich nicht auf den Propheten. Dieser berichtet - vor allem in bestimmten Versionen der Himmelfahrt - von den Begegnungen mit einigen seiner Vorgänger:

")Ich bin Moses begegnet‘, und er beschreibt ihn: ${ }^{31}$ `Es war ein Mann mit zitterndem Körper (?) und glattem Haar, wie einer aus dem Stamm der Shanû'a. Ich bin Jesus begegnet`, und er beschreibt ihn: ১Er war mittelgroß, von rötlicher Gesichtsfarbe, so als wäre er gerade dem Bade entstiegen. Ich sah Abraham, und ich bin es, der ihm von all seinen Nachfahren am meisten gleicht [...].« « ${ }^{32}$

Nach einer anderen Überlieferung sieht der Prophet im Traum Jesus die Ka'ba umschreiten. Er beschreibt ihn als einen sehr schönen Mann mit recht dunklem Teint und glattem Haar, das ihm über die Schultern fällt; Wassertropfen perlen auf seinem Gesicht, und seine Hände liegen auf den Schultern zweier Männer. Er bemerkt hinter sich einen kraushaarigen Mann, dem das rechte Auge fehlt, der ebenfalls die Ka'ba umkreist und sich, die Hände vorne auf den Schultern eines anderen Mannes (also hinter ihm), fortbewegt. Ihm wird erklärt, dass es sich bei diesem Mann um den Antichristen handelt (Bukhârî 2001, manâqib, Nr. 3440). Diese Beschreibung betont die Ähnlichkeit und den Unterschied zwischen Christus und seinem Widersacher. Die Wesen tragen das Zeichen ihrer Funktion, und ihre Körper bringen ihre höhere oder niedere Realität zum Ausdruck. Wenn das Siegel des Prophetentums - ein fleischiger Höcker, den der Prophet zwischen den Schulterblättern trägt - eines der physischen Zeichen ist, an denen ihn erkennen kann, wer die entsprechenden Voraussagen der heiligen Schriften kennt, ${ }^{33}$ so müssen sein gesamter Körper, die Gesamtheit seiner Gesten wie auch der gesamte Ablauf seiner Mission dem entsprechen, was die "Leute der Schrift « dem Koran zufolge über ihn wissen. ${ }^{34}$ In einer auf "Alî zurückgehenden Überlieferungen erzählt dieser, dass er vom Propheten als Missionar in den Jemen gesandt wurde. Dort wird er von einem Rabbiner, der ein Buch in der Hand hält, angesprochen und gebeten, Abû l-Qâsim (den Propheten) zu beschreiben. 'Alî beschreibt diesen in Wendungen, die mit der oben zitierten Überlieferung vergleichbar sind, und der Rabbiner fragt ihn: »Und was noch?« Als er antwortet, dass das alles sei, was ihm in den Sinn kommt, setzt der Rabbiner die Beschreibung fort, und 'Alî bestätigt sie. Ersterer bemerkt dann, diese Beschreibung sei im »Buch meiner Väter« (sifr âbâ’i) zu finden; er ruft in aller Kürze die Etappen von Muhammads Mission in Erinnerung und bezeugt seinen Glauben an ihn (Ibn Sa'd, o. J., Bd. 1, S. 412 f.). Hier ist nicht das wohlbekannte Thema der Ankündigung des Propheten in den heiligen Schriften von Juden und Christen von Interesse, sondern die Tatsache, dass diese sich in großen Teilen auf die Beschreibung eines Körpers stützt, der in all seinen Teilen und all seinen Taten vom Erbe des Prophetentums gezeichnet ist. ${ }^{35}$ Autoren wie Bayhaqî (gest. 458/1066; ders. 1985, Bd. 1., S. 194-275) und Ibn al-Jawzî (gest. 597/1200) übernehmen all die überlieferten Beschreibungen des Propheten und zählen jeden kleinsten Teil 
seines Körpers einzeln auf. Der letztgenannte Autor gibt eine äußerst detaillierte Beschreibung: Kopf, Stirn, Augenbrauen, Augen und Wimpern, Wangen, Nase, Mund und Zähne, Atem, Gesicht, Bart, Haar, Hals, Schultern, Rücken zwischen den Schulterblättern, Brust, Bauch, Nabel, Finger, Unterarme, Beine, Fersen, Füße, Gelenke, sein ausgewogener Körperbau, Größe, Haut, Farbe, Schönheit, Schweiß, das Siegel des Prophetentums. Dann folgen die moralischen und spirituellen Eigenschaften. ${ }^{36}$

Die Körper der Propheten - und des Propheten im Besonderen - lassen also gewisse Qualitäten und Tugenden erkennen, die das Normalmenschliche übersteigen; zum anderen wird ihr Leben mit der ihnen anvertrauten Mission identifiziert. Es kommt sogar vor, dass der Körper selbst zum Ort der Erscheinung Gottes wird. Der Koran lehrt die Gläubigen, dass der Körper, auch wenn er seiner Erscheinung nach Körper bleibt, letztlich einer anderen Wirklichkeit angehört. In Hudaybiyya reicht der Prophet den Gläubigen die Hand, damit sie den Treueid mit ihm erneuern; genau in diesem Augenblick ist seine Hand nicht mehr die seinige, sondern wird zum Vehikel der göttlichen Anwesenheit: »Die dir Treue geloben, geloben sie Gott. Gottes Hand ist auf ihrEr Hand.« (Koran 48:10.)

\section{Die Gefährten und der Körper des Propheten}

Allein der obenstehende Vers würde ausreichen, um die erstaunliche Verehrung der Gefährten für den Propheten verständlich zu machen - insbesondere für seinen Körper, so als würde sie der Kontakt zu seinem physischen Sein unmittelbar in die Gegenwart einer sakrosankten Wirklichkeit bringen.

\section{Der verehrte Körper}

Dieses Gefühl ist bei einigen Gefährten so ausgeprägt, dass es zu einer extremen Schamhaftigkeit führt, wie im bekannten Falle des 'Uthmân, der verkündete, mit seiner rechten Hand nie wieder sein Geschlecht berührt zu haben, seit er dem Propheten mit ihr den Treueeid schwor. ${ }^{37}$ Letzterer reagiert auf diese Schamhaftigkeit. Denn so lobenswert sie sicherlich ist, unterscheidet sich 'Uthmân durch sie von Abû Bakr und 'Umar, deren größere Intimität mit dem Propheten auch eine andere - entspanntere Beziehung zu seinem Körper mit sich bringt. Einer auf 'Âisha zurückgehenden Überlieferung zufolge befand sich der Prophet, mit unbedeckten Beinen bzw. nur zum Teil bedeckten Oberschenkeln, in ihrem Schlafgemach. Abû Bakr und 'Umar ersuchen nacheinander um Einlass und unterhalten sich mit dem Propheten. Als 'Uthmân seinerseits darum bittet, hereingeführt zu werden, setzt sich der Prophet auf, bedeckt sich, und dann empfängt er ihn. 'Âisha, die ihn daraufhin fragt, warum er sein Verhalten ändere, antwortet er: »Würde ich mich denn nicht vor einem Mann schämen, vor dem selbst die Engel Scham empfinden?« Einer anderen Version zufolge ist der Prophet lediglich in das Tuch (mirț) seiner jungen Ehefrau gehüllt. In dieser Garderobe empfängt er die ersten beiden, zieht sich dann aber wieder an, um den dritten zu empfangen, und erklärt seiner Frau: "Uthmân ist ein schamhafter (hayiyy) Mann; ich fürchte, wenn er mich in diesem Zustand sieht, wagt er nicht, mir von seiner Angelegenheit zu berichten. $\aleph^{38}$ Die Schamhaftigkeit 'Uthmâns ist von der Art, dass sie ihn selbst, den Propheten und die Engel in eine Beziehung zum Heiligen bringt, die einer gewissen Verhüllung bedarf, um aufrechterhalten zu werden. 


\section{Der geküsste Körper}

kehrt kann die Verehrung des Propheten aber auch in einem Verhalten extremer Vertraulichkeit zum Ausdruck kommen, das sich gleichermaßen durch seine Absicht und seine Umstände legitimiert sieht. Während der Schlacht von Badr, als der Prophet mit Hilfe eines Pfeils die Reihen ordnet, sticht er Sawâd bin Ghâziyya, einem der Anhänger (anșâr) aus Medina, ziemlich hart in den Bauch, woraufhin dieser ausruft: »O Gesandter Gottes, du hast mir wehgetan, und Gott hat dich mit Wahrheit und Gerechtigkeit gesegnet. Gewähre mir das Recht auf Vergeltung (le talion) (fa-aqid-nî)!« Der Prophet entblößt seinen Bauch und erwidert: »Nimm deine Rache!« Daraufhin nimmt Sawâd den Propheten in seine Arme und küsst ihm den Bauch. »- Was hat dich bewogen, dies zu tun, o Sawâd?« »O Gesandter Gottes, wir sind in der Gegenwart dessen, was du siehst, und ich wollte nicht von dir gehen, ohne meine Haut die Deine berühren zu lassen.« (Sîra, Bd. 1, S. 626). In einer ähnlichen Anekdote küsst ein anderer medinischer Anhänger, Sawâda bin 'Amr, den Körper des Propheten und meint hinsichtlich der Vergeltung: "Ich verzichte darauf, damit du dich am Tag der Auferstehung für mich einsetzt. « $^{39}$ Der Kontakt mit diesem heiligen Körper ist also, besonders an der Schwelle des Todes, Vehikel jenseitigen Heils. Das Wort Gottes wohnt in ihm, verwandelt ihn, besonders in seiner äußersten Schicht, die zu berühren den Gläubigen in sein erlösendes Licht taucht. Als der Prophet auf seinem Rückweg aus Ṭ̂̂’if den 'Addâs, einen aus Ninive stammenden, von den Banû Țaqiff versklavten Christen trifft, und dieser begreift, dass er einen Propheten vor sich hat, beeilt er sich, ihm Kopf, Hände und Füße zu küssen. Auf die Frage seines Herrn, warum er so etwas tue, antwortet er ihm wie folgt: "Mein Herr, es gibt auf der Welt keinen besseren als er ist, er hat mir etwas gesagt, das nur ein Prophet wissen kann" (Ibn Hishâm 2017 [1884], S. 175). Das Erkennen eines Propheten führt unweigerlich zur Bitte um Fürsprache, die durch den Kontakt zu dessen Körper unmittelbar aktualisiert wird.

\section{Der konsumierte Körper}

Allein der Kuss, so eifrig er auch gegeben sein mochte, genügte manch einem nicht. Einige Gefährten bemühten sich, alles aufzulesen, was der Körper des Propheten gegebenenfalls absonderte, um es sich anzueignen und es mit dem eigenen Fleisch und Blut zu vermischen. Diese Praktiken, die uns ebenso in Staunen versetzen, wie sie die Zeitgenossen in Staunen versetzt haben, erwachsen aus dem Glauben an eine Kontinuität zwischen irdischem Körper und Körper der Auferstehung. Ein vom Körper des Auserwählten, und sei es auch von seinen Ausscheidungen, durchdrungener Körper könnte nicht bestraft werden; seine Seele wäre damit gerettet. Nach dieser Repräsentation des Körpers geschieht alles so, als verwandele er die Seele, die er in sich trägt, auf dieselbe Art und Weise, wie sinnliche Begehren sie ins Verderben stürzen können. In Hudaybiyya ist ein als Unterhändler anwesender Abgesandter der Koreischiten erstaunt zu sehen, dass sich die Gefährten beeilen, das in dem Gefäß, an dem der Prophet seine rituellen Waschungen vollzogen hat, verbliebene Wasser $\mathrm{zu}$ trinken. ${ }^{40}$ Hier geht es lediglich um einen Kontakt mit seiner Hand, doch der Abgesandte beobachtet auch, dass sie Nasenschleim und Sputum des Propheten auffangen, um ihr Gesicht und ihren Körper sowie ihre Haare damit zu benetzen (Ibn Hishâm 1955, Bd. 2, S. 314; ders. 2017 [1884], S. 437). Einer anderen Überlieferung

Trivium, 29 | 2019 
zufolge fragt der Prophet die Gefährten, warum sie dies täten. Sie antworten daraufhin, dass sie seine Segenskraft (baraka) suchten. Ohne es ihnen zu verbieten oder auch nur vorzuwerfen, führt der Prophet sie gleichwohl auf den Pfad der Tugenden, denn er sagt zu ihnen:

"Wer will, dass Gott und sein Gesandter ihn lieben, der sage immer nur die Wahrheit, zahle zurück, was ihm anvertraut wurde, und tue seinem Nächsten kein Unrecht.« (Kândihlawî, 1968, Bd. 2, S. 580; nach Bayhaqî)

Der Prophet, der sich einem Aderlass unterzogen hatte, beauftragt den noch ganz jungen 'Abdallâh bin Al-Zubayr, das Blut irgendwo zu vergießen, "wo dich niemand sieht«. Letzterer nimmt das Gefäß, entfernt sich und trinkt den Inhalt. Bei seiner Rückkehr fragt ihn der Prophet:

" - O 'Abdallâh, was hast du mit dem Blut gemacht? - Ich habe es an den verstecktesten Ort gebracht, wo niemand es sehen kann. - Hast du es vielleicht getrunken? - Ja. - Und warum hast du das Blut getrunken? Wehe den Menschen vor dir und wehe dir vor den Menschen."

Abû 'Așim, einer der Übermittler dieser Überlieferung, fügt hinzu: »Man fragte sich, ob 'Abdallâhs Kraft nicht von diesem Blut herrührte." In einer anderen Version beantwortet der Knabe die Frage des Propheten, warum er so gehandelt habe, mit den Worten: "Ich wollte das Blut des Gottgesandten in meine Eingeweide leiten." Der Prophet gibt ihm darauf dieselbe Antwort und fügt noch hinzu $»$ Das Feuer wird dich nur heimsuchen, sofern Gott es geschworen hat", was den Exegeten zufolge auf den Vers verweist: „Es ist niemand unter euch, der nicht dort hinunterkäme« (Koran 19:71). ${ }^{41} \mathrm{Zu}$ Uhud sagt der Prophet über Mâlik bin Sinân, der das Blut aus seinen Wunden geleckt hat: »Mein Blut hat sich mit dem Seinen vermischt; das Feuer wird ihn nicht berühren. $\aleph^{42}$ Nichts anderes sagt er über Surra, die abessinische Dienerin seiner Frau Umm Salama; als er hört, dass sie seinen Nachttopf ausgetrunken hat, statt ihn zu leeren, spricht er: "Sie hat sich mit einem Gehege gegen das Feuer umgeben" (Kândihlawî 1968, Bd. 2, S. 581 f.).

23 Selbst wenn der Fall 'Abdallâh bin Al-Zubayrs ein wenig untypisch ist, weil die Aufnahme des Blutes seinen tapferen, ungestümen Charakter unterstreicht und sein tragisches Schicksal ankündigt, wird das Verzehren von Stoffen, die normalerweise unrein und verboten sind, nicht untersagt, sondern weist vielmehr auf die postume Glückseligkeit derer voraus, die sie zu sich nehmen. Entsprechend der Ambivalenz des Begriffs harâm wird das Unzulässige heilig, weil es der Glaube derjenigen verwandelt, die mit solchem Glauben an die Heiligkeit und eschatologische Wirklichkeit des Prophetenkörpers handeln, dass sie die irdischen Grenzen des (göttlichen) Gesetzes überschreiten und in den Schutz des beispiellosen Fürsprechers gelangen.

\section{Der konservierte Körper}

Der Islam kennt keinen Reliquienkult, sofern man unter Reliquien den toten Körper als ganzen oder seine Teile versteht. Der lebendige Körper des Propheten aber ist Gegenstand der oben beschriebenen Verehrung. Einmal besucht der Prophet die Mutter seines jungen Dieners Anas bin Mâlik. Während er seinen Mittagschlaf bei ihr hält, sammelt sie die Schweißtropfen, die sich von seinem Körper lösen, in einem kleinen Flakon auf. Als der Prophet erwacht und sie fragt, was sie da tue, antwortet sie ihm: »Es ist dein Schweiß, wir mischen die Tropfen in unser Parfum, weil er das beste Parfum ist, das es gibt.« (Muslim 1329 h, faḍ̂a'il 83, Bd. 7, S. 81) Und auch seine Haare werden zu 
seinen Lebzeiten und nach seinem Tod wie Reliquien behandelt. Khâlid bin Al-Walîd trug in seiner Mütze die Haare des Propheten, die er aufgesammelt hatte, als der Prophet nach seiner 'umra (bzw. Omrah, einer kleinen Pilgerfahrt nach Mekka) ins gewöhnliche Leben zurückkehrte. Diesen Haaren schrieb Khâlid bin Al-Walîd seine Siege zu (Bayhaqî 1985, Bd. 6, S. 249). Umm Salama, die Frau des Propheten, bewahrte dessen Haare in einer Art Silberglocke (juljul) auf. Wenn irgendjemand vom Fieber befallen oder vom bösen Blick getroffen war, nahm man die Haare heraus, tränkte sie in Wasser und bespritzte mit diesem anschließend das Gesicht des Patienten (Bukhârî 2001, libâs 66, Bd. 7, S. 374 f.; Bayhaqî 1985, Bd. 1, S. 236). Mittels der Haare wurde also auch nach dem Tod des Propheten die Verehrung seines Körpers fortgesetzt. Dieser Teil seines Körpers, den die regierenden Dynastien - so wie bestimmte ReliquienGegenstände (mukhallafât al-rasûl, âthâr al-nabî) - konservierten, verlängerte seine Anwesenheit auf Erden. Beim verstorbenen Propheten ging es nicht mehr darum, seinen Körper um jeden Preis zu berühren. Doch nun wurde die Erde von Medina, die schon zu Muhammads Lebzeiten geheiligt und heilkräftig war ${ }^{43}$ und die nach seinem Tod den heiligen Körper empfing, Gegenstand einer von zahlreichen Dichtern zum Ausdruck gebrachten Verehrung. So schreibt etwa der Autor der Burda:

„Kein Parfum lässt sich mit der Erde vergleichen, in der seine Knochen liegen. Selig ist der, der ihren Geruch atmet und sie mit seinen Lippen berührt.« (Bûșîîi 1973, S. 242, al-Burda, Vers Nr. 58)

Der Prophet ist gestorben und begraben, die Gegenwart seines Körpers aber macht die Erde (turba) seines Grabs, die Umgebung von Medina zu einer Reliquien-Kammer, so wie es die Gegend von Kerbela für die Schiiten und für wieder andere die Heiligengräber werden sollten. ${ }^{44}$ Die Vorstellung vom Propheten in seinem Grab ist allerdings nicht die eines toten Körpers. Auf einer Ebene, die gewiss subtiler als die alltägliche Körperlichkeit ist, werden Propheten in ihren Gräbern nämlich als lebendig angesehen. So berichtet der Prophet, auf seiner nächtlichen Reise an Moses vorbeigekommen zu sein, "als er in seinem Grab stehend betete« (wa huwa qẩim yusallî fí qabri-hi). ${ }^{45}$ Als er den Gefährten die Vorzüglichkeit des Freitags lehrt und ihnen nahelegt, an diesem Tag intensiv zu beten oder um Gnade für ihn zu bitten, »denn, so sagt er, euer Gebet wird mir vorgelegt« (fa-inna șalâta-kum ma'rûda 'alayya), fragen sich diese:

»Wie wird dir unser Gebet vorgelegt werden (?), wenn du nurmehr zu Staub zerfallene Knochen sein wirst (wa qad arimta)? - Gott, entgegnet er, hat der Erde verboten, die Körper der Propheten aufzuzehren« (Ibn Ḥanbal, o. J., Bd. 4, S. 8; Wensinck 1992, Bd. 1, S. 347).

Um welche Körper handelt es sich? Um Körper zwischen Diesseits und Jenseits, im Übergangsleben des Barzach, vermittels deren sich die Praxis der Anbetung in dieser Welt fortsetzt. Die Frage hat auch Autoren beschäftigt, die der Verehrung des Propheten dadurch Vorschub zu leisten versuchten, dass sie Anekdoten von der lebendigen und wahrnehmbaren Gegenwart des Propheten für diejenigen, die sein Grab besuchen oder sich in dessen Umgebung aufhalten, weitergaben ${ }^{46}$ - so wie etwa die des Sa î̀ bin Al-Musayyib (gest. 94/712-713), der sich während der Ereignisse von al-Ḥarra (63/683) in der Nähe des Grabmals eingeschlossen fand; obwohl drei Tage lang in der Moschee des Propheten nicht zum Gebet gerufen wurde, war Sa'îd durch ein vom Grab kommendes Murmeln über die Gebetszeiten informiert (Dârimî, o. J., muqaddima 15, Bd. 1, S. 44). 
27 Nach dem Vorbild der Märtyrer: tot, aber lebendig bleiben die Körper der Propheten Zeugen für die Menschen in dieser und der anderen Welt - also von Leben erfüllt; nämlich von dem Leben der die Grenzen des gewöhnlichen körperlichen Lebens hinter sich lassenden Geister, das sich den mit spiritueller Empfindsamkeit begabten Wesen auf quasi wahrnehmbare Weise offenbart. Dass der Prophet einerseits beteuert, dass "Gott der Erde verboten hat, die Körper der Propheten aufzuzehren«, und andererseits sagt: »Jedes Mal, wenn jemand mich grüßt, schickt Allah meine Seele zu mir zurück, so dass ich ihm den Gruß erwidern kann «, ${ }^{47}$ lässt darauf schließen, dass auch der Körper in seinem Grab Vehikel einer Gegenwart und eines Einflusses bleibt. So wird verständlich, dass man den Propheten wie zu Lebzeiten besucht und grüßt. Diese Überlieferung bildet zusammen mit vielen anderen die Grundlage des Gräberbesuchs (ziyârat al-qubûr). Wie alle religiösen Überlieferungen wirft sie die Frage nach einer Fortdauer der Beziehung zwischen Körper und Seele im Grab auf. Eine prophetische Tradition lehrt, dass »es im Menschen einen Knochen gibt, den die Erde niemals aufzehrt und von dem ausgehend er am Tage der Auferstehung neu zusammengefügt wird. - Welchen, fragte man? - das Kreuzbein bzw. sacrum ('ajm oder 'ajam al-fanab) «. ${ }^{48}$ Es ist bezeichnend, dass die mit dem verstorbenen Körper in Kontakt stehende Erde, die turba, am Ende gleichbedeutend wurde mit dem über dem Grab errichteten Gebäude, der qubba: zunächst ein Zelt und später jene architektonische Form, die den Kubus mit der Hemisphäre verbindet und darin die Vereinigung von Himmel und Erde symbolisiert.

An dieser eschatologischen Dimension des Körpers haben alle Wesen teil, weil sie alle zur Auferstehung gerufen werden. Die Frage der Erde und des Körpers der Auferstehung, ${ }^{49}$ so wie Koran und Sunna sie lehren, sprengt allerdings den Rahmen dieser Untersuchung. Erinnern wir uns einfach, dass das primordiale Licht des Propheten, das im Zuge seiner irdischen Geburt Gestalt annahm, der Grund dafür ist, dass er als Erster auferstehen wird:

»Ich bin der Herr der Söhne Adams am Tag der Auferstehung, das sage ich ohne Stolz (wa lâ fakhr); ich bin der Erste, für den sich die Erde am Tag der Auferstehung spalten wird, das sage ich ohne Stolz; ich werde am Tag der Auferstehung der erste Fürsprecher sein und sage das ohne Stolz.« ${ }^{50}$

Nicht immer scheint die Sunna eine besondere Lehre über den Körper des Propheten im Jenseits bereitzuhalten. Der Koran spricht ganz allgemein von der "jenseitigletzte[n] Schöpfung [29:20]/andere[n] Schöpfung [53:47]« (al-nash'at al-âkhira), in der der Mensch wiedererschaffen wird (Koran 29:20 und 53:47), von der Rolle des Körpers als Zeugen für die Taten des Menschen während des Gerichts (Koran 24:24; 36:65; 41:20 f.), vom ursprünglichen adamitischen Körper, den jeder Mensch beim Eintritt in das Paradies wiederfindet. ${ }^{51}$ Die Menschen im Jenseits, insbesondere ihre Gesichter, werden je nach ihrem postumen Schicksal vom göttlichen Licht gezeichnet oder des göttlichen Lichts beraubt sein. In einer seiner Anrufungen bittet der Prophet Gott um eine vollkommene, innere und postume, Erleuchtung der Wahrnehmungsorgane, aber auch aller Körperteile, wodurch er seine im Jenseits fortgesetzte Rolle als Gefäß oder Tempel des Lichts unterstreicht:

»[...] O mein Gott, bring ein Licht in mein Herz und ein Licht in mein Grab, ein Licht vor mich und ein Licht hinter mich, ein Licht zu meiner Rechten und ein Licht zu meiner Linken, ein Licht über mich und ein Licht unter mich, ein Licht in mein Gehör und ein Licht in meine Augen, ein Licht in meine Haare, ein Licht in meine Haut, ein Licht in mein Fleisch, ein Licht in mein Blut und ein Licht in meine Knochen [...] (Tirmidhî, o. J., Bd. 4, S. 235). 
Die Körper der in dieser Welt Geläuterten werden die Spur der Läuterung in die andere Welt tragen. Sie werden gleich den Pferden eine weiße sternförmige Blesse [Bukhârî: "ein Mal«] auf der Stirn und weiße Marken an den Füßen [Bukhârî: "Reifen am Fußgelenk «] tragen, und an diesem Zeichen wird der Prophet sie erkennen und an seinem Wasserbecken willkommen heißen, um ihren Durst zu löschen. ${ }^{52}$ Dank der im Diesseits vollzogenen Körperrituale geht dieses Bild der Erleuchtung des auferstehenden Körpers alle Gläubigen an. Der Prophet hingegen erfüllt hier die Funktion eines Vermittlers, eines Fährmanns zu anderen eschatologischen Orten. Das Bild des Sterns und der hellen Marken legt die Vorstellung nahe, dass der Körper auf der Reise von dieser Welt in die andere vor allem das Reittier der Seele ist. Die Sorgfalt, die man auf ihn verwendet, und die Rituale, die er auszuführen erlaubt, sind lediglich sichtbarer Ausdruck des inneren Wegs der Seele und ihrer Läuterung. All dies ist für den Propheten, der zu den Menschen zurückkehrt, um sie zu Gott zu rufen, bereits erreicht. In dieser Welt galt sein Körper den Gläubigen zugleich als Vorbild und als Mittel der Fürsprache, denn der Körper ist für den Propheten wie für den Heiligen ein Halt für den Segen und ein Unterpfand der Fürbitte. In der anderen Welt sind die Körper der Menschen nicht mehr Schleier, sondern Enthüller ihres Zustands; für den Propheten zählt allein seine Funktion eines Zeugen und Fürsprechers. ${ }^{53}$

\section{Auf dem Weg zu einer Schlussfolgerung: der Körper und die Offenbarung}

Im Koran und in der Sunna sowie in der spirituellen Tradition des Islam zielen die eschatologischen Erzählungen darauf ab, sich in einem ersten Moment des Schicksals bewusst zu werden und in einem zweiten des Ursprungs des Menschen; in beiden Momenten ist der Körper gegenwärtig und Zeuge. Das Ende der Welt in seiner doppelten mikro- und makrokosmischen Dimension: Tod des Einzelnen und Zerstörung der Welt, gefolgt von sukzessiven Phasen des Jenseits, ist nur scheinbar ein Ende. Es führt den Menschen in Wahrheit zu seiner ursprünglichen Schöpfung zurück, an die im Koran so oft erinnert wird. Das gilt auch für die unvollendeten Zyklen der Menschheit, von denen in den prophetischen Geschichten erzählt wird. Die Erinnerung an die aufeinanderfolgenden Bündnisse mit den Söhnen Israels in der Sure al-A'râf endet mit der Beschwörung eines ursprünglichen Paktes:

»Als dein Herr aus den Kindern Adams, aus ihrem Rücken, ihre Nachkommen nahm und sie gegen sich selbst zeugen ließ. `Bin ich nicht euer Herr? - Sie sagten:

,Gewiss doch! Wir bezeugen es.« (Koran 7:172)

Der Körper ist bei dieser Verpflichtung schon gegenwärtig. Beim Lesen des Korans wundert man sich über die Bedeutung, die dem Körper des Menschen und allen Phasen seiner Entwicklung zugebilligt wird, angefangen beim Ausstoß des Spermatropfens. Die Sure al-Qiyâma (75), »die Auferstehung«, illustriert auf besonders verdichtete Weise diese Rückkehr vom Ende an den Anfang, die dem Körper seine Rolle als Gefäß der Offenbarung verleiht und ihn dadurch sakralisiert. Zunächst wird die Auferstehung in den kleinsten körperlichen Einzelheiten in Erinnerung gerufen, dann durch die kosmischen Zeichen, die ihr vorausgehen, sowie das Urteilen über die Taten, deren sich der Mensch schon auf Erden bewusst ist. Ein Abschnitt scheint hier den Rhythmus der Sure zu unterbrechen, bildet aber in Wirklichkeit deren Zentrum. Es wird dem Propheten empfohlen, seine Zunge nicht übereilt zu bewegen, um nicht die Ankunft 
der Offenbarung zu überstürzen, weil Gott die Zusammenstellung und die erste Rezitation des Korans obliegt. Unausgesprochen wird diese Eile des Propheten auf einer anderen Ebene in Beziehung gesetzt mit der Hast des normalen Menschen, der »das Flüchtige« liebt, mit anderen Worten: das unmittelbare Leben auf Kosten des anderen, in dem sich Menschen durch ihre strahlenden oder finsteren Gesichter unterscheiden werden. Von der Beschwörung des Jenseits kehrt die Sure zur Beschwörung des sterbenden Menschen und der Position seines Körpers in dem Moment zurück, da die Seele zum Herrn geschickt wird. Denen, die die Offenbarung und ihre Gebote in den Wind schlagen, wird in Erinnerung gerufen, dass die Menschen nicht umsonst geschaffen wurden und dass sie genau als die Männer oder Frauen auferstehen werden, als die sie aus einzelnen Spermatropfen geschaffen wurden. Die zyklische Struktur der Sure und das Beharren auf dem Zusammenfügen und Wiederzusammenfügen des Körpers kann man mit dem fortschreitenden Gebot des Korans in Verbindung bringen, an das sich der Prophet bis in die Bewegungen seines Körpers hinein anpassen muss. Es lässt die tiefen Gründe für die Heiligkeit des Propheten-Körpers erahnen. ${ }^{54}$ Von der Offenbarung ist im Koran die Rede sowie in den Überlieferungen, die von den physischen Auswirkungen, etwa dem Prozess, durch den das Wort Fleisch und wieder Wort wird, handeln. ${ }^{55}$ Die drei erdrückenden Umarmungen des Engels, die den Propheten dazu bringen, noch einmal das Wort iqra' (Rezitiere!) zu sagen (den Beginn des Korans zu zitieren), lassen sich mit einem physischen oder initiatorischen Tod vergleichen, der Zugang zu einem anderen Zustand oder Grad des Bewusstseins gewährt. Die verschiedenen Abschnitte, die der Koran Mariens Empfängnis des Wortes oder Geistes widmet, zeigen auf die denkbar klarste Weise die Rolle des Körpers bei der Übermittlung des Wortes:

»Und Maria, Imrans Tochter, die ihre Scham schützte. Da bliesen wir in sie von unserem Geist. Sie glaubte den Worten ihres Herrn und seinen Schriften und gehörte zu den Gehorsamen.« (Koran 66:12)

Die Erwähnung der Scham preist das Jungfernhäutchen des Körpers und des Geistes.

Maria gebärt eine Inkarnation des Wortes und des Geistes, wobei sie am liebsten gestorben wäre, und deshalb soll ihr Körper gestärkt werden (Koran 19:22-26). Der Prophet seinerseits identifiziert sich mit allen prophetischen Vorbildern, die er vorfindet: vom leidgeprüften Körper Hiobs bis zum durch die Himmelfahrt sublimierten und wieder zu den Menschen herabgestiegenen Körper. Auf der Erde vereinigt sich sein wohlriechender Körper mit dem seiner Ehefrauen. Er macht aus der Ehe seine Sunna, also einen Weg zu Gott, wodurch er im doppelten Sinne des Wortes harâm alles aus der körperlichen Vereinigung Stammende heiligt. Genauso, wie die Gläubigen beiderlei Geschlechts seinen heiligen Körper verehren, müssen sich die seine Intimität bezeugenden Ehefrauen von einem gewissen Moment an hinter den Vorhang ihrer Heiligkeit zurückziehen, insofern sie Ehefrauen des Propheten und Mütter von Gläubigen sind (Koran 33:53 und 6). Der Körper ist ein offenes Buch, und es gibt Dinge, die man auf keinen Fall offenbaren darf, andere hingegen, die man genießen kann. 


\section{BIBLIOGRAPHIE}

\section{Primärtexte}

Abû Dâwûd [Abū-Dā'ūd as-Siğistānī] (o. J.): Sunan, hg. von Muhammad Muhyîi l-Dîn 'Abd alHamîd, 4 Bde., Beirut.

- (2015-2017): Sunan ‘Abi Dāwūd, 5 Bde., übers. von Neil Bin Radhan, Heilbronn: Darulkitab. Abû Nu'aym al-Ișfahânî (1320 h.): Dalâ'il al-nubuwwa, Hyderabad / Beirut.

- (o. J.): Hilyat al-awliyấ, 10 Bde., Kairo.

Bayhaqî (1985): Dalâ'il al-nubuwwa, hg. von 'Abd al-Mu'țî Qal'ajî, Beirut.

Bukhârî (2001): Șahịh, zweisprachige Ausgabe, 8 Bde., Beirut.

- [BuHāāryy, Abū 'Abdullāh Muḥammad Ibn Ismā'îl al-] (2015): Șaḥịh Al-BuH̆āryy, gekürzte Ausgabe, Düsseldorf: IB Verlag islamische Bibliothek.

Bûșîrî [Būṣīīi, Sharaf al-Dīn Muhammad ibn Sa'īd] (1973): Dîwân al-Bûṣ̂îî, hg. von M. Sayyid Kîlânî, Kairo.

Dârimî [Dārimī as-Samarqandī, 'Abdallāh 'Abd-ar-Raḥmān ad-] (o. J.): Sunan, 2 Bde., Beirut.

Fîrûzâbâdî [Fīrūzābādī; Muhạammad Ibn-Ya'qūb al-] (1966): Al-Ṣilât wa l-bushar fi l-ṣalât 'alâ khayr al-bashar, Damaskus: Manšūrāt Dār at-Tarbiya.

Ibn ‘Alawî al-Mâlikî al-Ḥasanî, Al-Sayyid M. (1993): Mafâhîm yajibu an tuṣaḥhah, Marokko.

Ibn 'Arabî [Ibn al-'Arabī, Muḥammad b 'Alī] (1946): Fuṣûs al-ḥikam, hg. von Abû al-'Alâ' 'Afîfî, Kairo: Ğamâ'at Ihyầ' al-Falsafa.

- (1329h. [1911]): Al-Futûhât al-makkiyya, Kairo, 4 Bde. [dt. Teilübers.: (2009): Abhandlung über die Liebe: aus den Futûhât al-Makkiyyah, übers. von Maurice Gloton und Wolfgang Herrmann, Zürich: Chalice].

- (1919): Al-Tadbîrât al-ilâhiyya fi iṣlâh al-mamlakat al-insâniyya, hg. von H. S. Nyberg, Leiden: E. J. Brill.

- [Ibn al-Arabī] (1986): Die Weisheit der Propheten, übers. von Hans Kofler, Graz: Akademische Druck- und Verlagsanstalt. [= Dt. Übers. von Ibn 'Arabî 1946.]

Ibn al-Jawzî [Ibn al-Jawzī, Abū al-Faraj 'Abd al-Raḥmān ibn 'Alī] (1976): Al-Wafâ' bi-aḥwâl alMuștafâ, hg. von M. Zuhrî Al-Najjâr, 2 Bde, Riad: Mu'assassat al-Sa'idiyah.

Ibn Ḥajar al-Haytamî [Ibn Ḥajar al-Haythamī, Ahmad ibn Muḥammad] (1967): Majma al-zawấid, 10 Bde., Beirut: Dar al-Kitab.

- (2002), Al-Durr al-manḍ̂d fi l-ṣalât wa l-salâm 'alâ șâhib al-maqâm al-mahûud, hg. von Ḥasanayn M. Makhlûf, Kairo: Dar al-Jawami' al-Kalam.

Ibn Ḥanbal (o. J.): Musnad, 6 Bde., Beirut.

Ibn Hishâm (1955): Al-Sirra al-nabawiyya, hg. von Mușțafâ al-Saqqâ' et al., 4 Bde., 2. Aufl., Kairo. 
- (2017 [1884]): Die Sira, das Leben des Propheten Mohammed. Nach Mohammed Ibn Ishak, bearbeitet von Abu Mohammed Abd el-Malik Ibn Hischam, ungekürzte Ausgabe, nach der Übersetzung von Dr. Gustav Weil, hg. von R. Lunnebeck, München: Arnulf Blecken.

Ibn Kathîr [Ibn-Katīr, Ismā'îl Ibn-'Umar] (1986): Al-Bidâya wa l-nihâya, Beirut: Dâr al-Fikr, 8 Bde.

- (2012): Der Anfang und das Ende, übers. von Umm Hamza Sidi Moussa, 4 Bde., Bonn: Rauda.

Ibn Mâja (1972): Sunan, hg. von M. Fu’âd ‘Abd al-Bâqî, 2 Bde., Kairo.

Ibn Manẓ̂r [Muhammad b. Mukarram] (1995): Lisân al-'Arab [Wörterbuch der arabischen Sprache], 18 Bde., hg. von Amîn Muhammad 'Abd-al-Wahhâb, Beirut: Dâr Ihyyâ' at-Turât al'Arabî.

Ibn Qayyim Al-Jawziyya [Ibn-Qaiyim al-Ğauzīya, Muhammad Ibn-Abī-Bakr] (1968): Jalâ' al-afhâm fi șalât 'alâ khayr al-anâm, hg. von Taha Yûsuf Shâhîn, Kairo: Maktabat Anṣâr as-Sunna alMuhammadîya.

Ibn Shabba [Ibn-Šabba an-Numairī, Abū-Zaid 'Umar] (1410 h. [1990]): Târîkh al-Madìna almunawwara, hg. von Fahîm M. Shaltût, Beirut.

Ibn Sa'd (o. J.): Al-Ṭabaqât al-kubrâ, hg. von I. 'Abbâs, Beirut: Dâr Șâdir.

Idris, H. R. (Hg.) (1959): Manâqib d'Abû Ishâaq al-Jabaniyâni et Manâqib de Muhriz bin Khalaf, übers. von H. R. Idris, Paris: PUF.

Iyâd al-Qâḍ̂i (o. J.): Al-Shifấ' bi-ta' rîf ḥuqûq al-Muștafẩ, Beirut.

Kândihlawî, Y. (1968): Hayât al-ṣaḥâba, Beirut, 4 Bde.

Muslim [Muslim Ibn al-Hajjaj] (1329 h. [1911]): Șaḥịh [Muslim], 8 Bde., Istanbul.

- (2014): Șaḥiḥ Muslim, übers. von Fadlallah Ksiks, 2 Bde., Düsseldorf: IB Verlag islamische Bibliothek.

Muttaqî al-Burhânpûrî, 'Alî [Muttaqī, Alī Ibn-'Abd-al-Malik al-] (1971): Kanz al-'ummâl fi sunan alaqwâl wa l-afâl, 16 Bde., Aleppo.

Nasâ'î [Nasā'î, Ahmad b. 'Alī al-] (1930): Sunan, hg. von Ḥasan M. al-Mas' ûdì, 8 Bde., Beirut: Dâr Ihyâ̂' al-Turât al-'Arabî.

Qasțallânî, Aḥmad ibn Muḥammad (1326h./1907): Al-Mawâhib alladuniyya bi-l-minaḥ almuhammadiyya, 2 Bde., Kairo.

Qurțubî [Qurtubī, li-Abī 'Abd Allāh Muhammad b. Ahmad al-Ansārī al-] (1952-1967): Jâmi' albayân, 20 Bde., Kairo: Matba'at Dâr al-kutub al-misrîyah.

Samhûdî [Samhūdī, 'Alī ibn 'Abd Allāh] (1984): Wafấ' al-wafâ' bi-akhbâr dar al-Mușțafâ, hg. von Muḥammad Muhyî al-Dîn 'Abd al-Ḥamîd, Beirut: Dâr Iḥyâ' al-Turât al-'Arabī.

Subkî, T. al-Dîn [Subkī, Taqī al-Dīn 'Alī ibn 'Abd al-Kāfī] (1371 h./1951): Shifấ' al-siqâm fi ziyârat khayr al-anâm, Beirut (o. J.)

Suyûțî [Suyūṭī, 'Abd al-Raḥmān b Abī Bakr al-] (1967): Al-khașâ'iṣ al-kubrâ, hg. von Muhammad Khalil Harrâs, 3 Bde., Kairo: Dâr al-kutub al-hadithah.

- (1975 [1352 h.]): Inâ' al-azkiya' bi-ḥayât al-anbiyâ' in: ders., al-Hâwî̀ li-l-fatâwî, 2 Bde., Beirut: Dâr al-Kutub al-'Ilmîyah.

Ṭabarî, M. (gest. 694 h./1295) [Ṭabarī, Muhibb al-Dīn Aḥmad ibn 'Abd Allāh] (1984), Al-Riyâd alnaḍira fi manâqib al-'ashara, 4 Bde., Beirut: Dâr al-Kutub al- 'Ilmîyah. 
Tirmidhî [Tirmidhī, Muhammad ibn 'Īsá] (2000): Sunan at-Tirmidīi, 2 Bde., Vaduz: Thesaurus Islamicus Foundation.

- (1985): Awșâfal-nabî, hg. von Samîh 'Abbâs, Beirut: Dâr al-Jîl.

\section{Sekundärliteratur}

Amir-Moezzi, M. A. (1992): Le guide divin dans le shî'isme originel. Aux sources de l'ésotérisme en Islam, Lagrasse: Verdier.

Andrae, T. (1918): Die Person Muhammeds in Lehre und Glauben seiner Gemeinde, Stockholm: Nordstedt.

Corbin, H. (1960): Terre céleste et corps de résurrection. De l'Iran mazdéen à l'Iran shi'ite, Paris: BuchetChastel.

Guénon, R. (1987): Der König der Welt, übers. von Ursula von Mangoldt, Freiburg im Breisgau: Aurum 1987.

Hamidullah, M. (1960): „Une ambassade du calife Abû Bakr auprès de l'empereur Héraclius et le livre byzantin de la prédiction des destinées«, Folia Orientalia, Bd. 2.

Meyer, F. (2005): Bemerkungen zur Muhammed-Verehrung, Teil 2: Die Taṣliya in sufischen Zusammenhängen, hg.von Bernd Radtke, Leiden: Brill.

Schimmel A. (1981): Und Muhammad ist sein Prophet: die Verehrung des Propheten in der islamischen Frömmigkeit, Düsseldorf: Diederichs.

Vâlsan M. (1962): „Le coffre d'Héraclius et la tradition du >tâbût adamique«, Etudes Traditionnelles 371, S. 141-144; 374-5, S. 266-73 und S. 37-45. [Wiederabdruck in: ders., L'Islam et la Fonction de Rene Guénon, Nuits-Saint-Georges: Science Sacrée 2016, S. 147-170.]

Wensinck, A. J. (1992): Concordance et indices de la tradition musulmane, 8 Bde., Leiden: Brill.

\section{NOTES}

1. Koran 26:193-194: »Der vertrauenswürdige Geist hat ihn herabgebracht auf dein Herz, damit du zu den Warnern gehörst.« [Alle Koranzitate hier und im Folgenden nach der Übersetzung von Hans Zirker; A.d.Ü.]

2. Koran 2:126: »Und als Abraham sagte: ^Herr, mach dies zu einem sicheren Ort [...]««, und 14:35.

3. Als der Prophet bei seiner Rückkehr aus Khaybar Medina erblickt, sagt er: »O mein Gott, ich erkläre das Gebiet zwischen diesen beiden Coulees schwarzer Steine für heilig (uharimmu), so wie es Abraham für Mekka getan hat.« Bukhârî (2001), jihâd 71, Nr. 2889 und 74, Nr. 2893. Für die anderen Versionen vgl. Wensinck (1992), Bd. 1, S. 452.

4. Neben fünf dem Propheten gewährten Privilegien, Bukhârî (2001), tayammum 1, Nr. 335. Vgl. die Verweise auf die anderen Versionen in Wensinck (1992), Bd. 2, S. 271.

5. In der Version Ibn Ishâqs (gest. 150/767): »[...] O ihr Leute, haltet euer Gut und euer Blut heilig, bis ihr eurem Herrn begegnet, so heilig wie euch dieser Tag und dieser Monat ist [...]« (Ibn Hishâm 2017 [1884], S. 572).

6. Für die verschiedenen Darstellungen der Person des Propheten und ihre Weiterentwicklung im Islam bleibt Andrae (1918) unübertroffen. Bezüglich der Liebe und der Verehrung für den propheten im Allgemeinen - und im Sufismus im Besonderen - vgl. auch Schimmel (1981). 
7. Der Artikel "Jism« in der Encyclopaedia of Islam (Second Edition) ist vor allem von der philosophischen Tradition inspiriert.

8. Koran 7:147 und 20:88. In der Geschichte von Salomon ebenso wie in der vom Goldenen Kalb drückt das Verb alqâ (»schleudern/auswerfen/ausspucken/übertragen/werfen/projizieren«, projeter) das Herabsteigen und Eindringen eines Geistes in einen Körper aus. Dasselbe Verb wird für die Übertragung des göttlichen Wortes auf Maria (Koran 4:171 [dort: »entbot«]), des Geists der Offenbarung auf die Propheten und des Korans auf Muhammad als "schwer lastendes Wort" (ebd. 73:5) verwendet, was die Sunna in sehr physischen Begriffen ausdrückt.

9. Koran 10:92 und Qurțubî (1952-67), Bd. 8, S. 380.

10. Im Hadith zu Gabriel erscheint dieser in Gestalt eines weißgekleideten Reisenden (Muslim 1329 h., Bd.1, S. 28-30). Nach einer anderen Überlieferung präsentiert sich der Engel dem Propheten in Gegenwart von dessen Ehefrau Umm Salama in Gestalt eines Gefährten, des Dihya al-Kalbî (Bukhârî 2001, Die Vorzüglichkeit des Koran (fậâ'il al-qur'ân) 1, Nr. 4980). Zu weiteren ähnlichen Überlieferungen, unter Nennung anderer Gefährten, vgl. Bayhaqî (1985), Bd. 7, S. 6578.

11. Ibn Manẓûr (1995): Lisân al-‘Arab, Bd. 2, S. 281 f. (jasad) sowie S. 284 (jism).

12. Zu diesen beiden Ausdrücken vgl. Wensinck (1992). Der Prophet antwortet beispielsweise auf die Frage, wann sich ihm das Prophetentum aufgedrängt habe: »Als Adam zwischen dem Geist und dem Körper war (bayna l-rûh wa l-jasad)«, Tirmidhî (2000), Bd. 2, S. 925. Vgl. auch Ibn Ḥanbal (o. J.), Bd. 4, S. 66.

13. Über die Weiterentwicklungen dieser grundlegenden Erzählung im Schiismus vgl. AmirMoezzi (1992), S. 145-154.

14. Koran 16:98: »Wenn du dEn Koran vorträgst, dann suche Zuflucht bei Gott vor dEm gEstEinigten Satan!«

15. Zur Öffnung des Herzens vor dem Mírâj vgl. Bukhârî (2001), Die Vorzüglichkeit der Prophetengefährten (mânaqib al-Anșâr) 42, Nr. 3887.

16. $\mathrm{Zu}$ dieser umstrittenen Frage und den verschiedenen Versionen des Berichts siehe u. a. Ibn Kathîr 1986, Bd. 3, S. 108-117. Die fünf täglichen Gebete, die im Zuge der Himmelfahrt zum Gesetz werden, besiegeln die Rolle des Körpers im Vollzug der Riten.

17. Bukhârî (2001), 'alât 12, Nr. 370; siehe auch Wensinck (1992), Bd. 5, S. 82.

18. Ibn Hishâm 1995, Bd. 1, S. 182. Von diesem Mönch heißt es, er habe sich daran gemacht, "gewisse Teile seines [Muhammads] Körpers (ashyâ' min jasadi-hi) nach Maßgabe der Beschreibung, die er von ihm hatte, zu betrachten.«

19. Salmân berichtet: "Als der Erwählte Gottes sah, dass ich hinter ihm vorbeiging, wusste er, dass ich etwas zu erkennen suchte, was mir schon beschrieben worden war. Er ließ sein Obergewand von seinen Schultern fallen. Ich sah das Siegel und erkannte es wieder. Sogleich stürzte ich auf ihn zu, umarmte ihn und weinte [...].« Zu diesem »Siegel« siehe u. a. auch die von Tirmidhî zusammengestellten Überlieferungen (1985, S. 37-44). Vgl. auch unten die Literaturangaben zur Beschreibung des Körpers des Propheten.

20. Manche zogen sich die Kleider aus, wenn sie auf ihrer Pilgerfahrt die Katba umrundeten (Ibn Hishâm 1955, Bd. 1, S. 202 f.).

21. So berichtet es 'Â'isha; vgl. 'Iyâḍ (o. J.), Bd. 1, S. 66.

22. Nasâ̂̂ 1930, Bd. 7, S. 61; Ibn Ḥanbal (o. J.), Bd. 3, S. 128. Vgl. den Kommentar zu diesem Hadith bei Ibn 'Arabî (1946), S. 216-226.

23. Muslim (1329 h.), (șalât 112), Bd. 1, S. 320. Über das Sehen nach hinten wie nach vorne vgl. ebenfalls Bayhaqî (1985), Bd. 6, S. 73; und über das Sehen bei Tage wie bei Nacht ebd., S. 74 f.

24. "Ich habe niemals einen Seiden- oder Brokatstoff berührt, der zarter gewesen wäre als die Handfläche des Propheten, noch habe ich einen Geruch geatmet, der stärker parfümiert gewesen wäre als der des Propheten«, sagt wiederum 'Â’isha, nach Bukhârî (2001), manâqib 23 (șifat al-nabî 
), Nr. 3561. Siehe auch Muslim (1329 h.), fadẩil 80-85, Bd. 6, S. 80-82 sowie Ibn Ibn Ḥajar alHaytamî (2002), Bd. 8, S. 282 f.

25. Ein andermal legt er seine Hand auf das Euter eines Schafs, das daraufhin wieder Milch gibt (Bayhaqî 1985, Bd. 6, S. 84).

26. Zu weiteren Heilungen, bei denen er zugleich anhaucht und spuckt, vgl. Bayhaqî (1985), Bd. 6, S. $173 \mathrm{f}$

27. Koran 17:82: „Wir sEndEn vom Koran hinab, was HEilung und BarmhErzigkEit ist für diE GläubigEn. Denen abEr, die Unrecht tun, mEhrt Er nur den Verlust.«

28. Zur Physiognomie vgl. T. Fahd, »firâsa«, Encyclopaedia of Islam (Second Edition), Bd. 2, S. 937 f.

29. Siehe die Gesamtheit der Überlieferungen, die zum größten Teil im Anschluss an 'Alî von Ibn Sa'd zusammengestellt wurden: Ibn Sa'd (o. J.), Bd. 1, S. 410-425 (fikr șifat rasûl Allâh); Tirmidhî (1985), S. 21-35 (dieselbe Überlieferung wird dort im Anschluss an 'Alî von Ibrâhîm, dem Sohn des Muhammad bin al-Ḥanafiyya wiedergegeben); Ibn Kathîr (1986), Bd. 6, S. 11-29. Vgl. auch andere Versionen bei Ibn Shabba (gest. 264/877); ders. (1410 h.), S. 602-616; Suyûțî (1967), Bd. 1, S. 178-190; Muttaqî al-Burhânpûrî (1971), Bd. 7, S. 161-177 (nach Suyûțîs Jam ‘ al-jawâmî) sowie die Ausführungen von Qasțallânî (1326 h./1907), Bd.1, S. 248-287 (dieser Autor schließt in die Aufzählung der physischen Qualitäten eine Passage über die Reinheit und Sprachgewalt der Zunge [langue] des Propheten ein, wobei er mit dem körperlich-linguistischen Doppelsinn von "Zunge« spielt). Vgl. auch Andrae (1910), S. 199-212. Diese Porträts des Propheten hätten eine gesonderte Studie verdient, sowohl unter dem Gesichtspunkt des ganz besonderen Vokabulars, das sie verwenden, als auch unter dem eines möglichen Vergleichs mit den Abhandlungen zur Physiognomie und den Beschreibungen der Gründerfiguren anderer religiöser und spiritueller Traditionen.

30. Dieser Ausdruck stammt aus den Hadithen. Man findet ihn insbesondere in einer Überlieferung, der zufolge Hạan, der Sohn 'Alîs, Hind Ibn Abî Hâla, seinen Onkel mütterlicherseits (einen Sohn Khadîjas) nach der körperlichen Erscheinung des Propheten befragt habe, weil »er dafür bekannt war, die Hilya des Propheten kalligrafisch zu gestalten« (kâna wașșâfan 'an hilyat al-nabî), Tirmidhî 1985, S. 27 sowie Ibn Sa'd (o. J.), Bd. 1, S. 422.

31. Zusatz des Berichterstatters.

32. Bukhârî (2001), manâqib, Nr. 3437. Vgl. auch den Bericht über den Mírâj bei Ibn Hishâm (1955), S. 400.

33. Wie in den Erzählungen des Mönchs Bahîrâ, des Salmân al-Fârisî (Ibn Hishâm 1955, Bd. 1, S. 182 f. und 220) oder auch des Mönchs Nestor, die der Bahîrâs weitgehend gleicht, als der Prophet im Alter von 25 Jahren nach Syrien zurückkehrt (Abû Nu'aym al-Ișfahânî 1320 h., S. 54).

34. Koran 7:157: »DiE dEm GEsandtEn, dEm schriftunkundigen ProphEtEn, folgen, den sie bEi sich in der Tora und im EvangElium verzeichnet finden [...].«

35. Man muss ebenfalls an die Überlieferungen zu den Bildern der und des Propheten erinnern, die den Gefährten gezeigt wurden und auf denen diese den Propheten wiedererkannten. Dies soll sich entweder zu Lebzeiten des Propheten in einem Kloster im syrischen Bușrâ zugetragen haben, oder aber während des Kalifats des 'Abû Bakr in Damaskus, als Heraklius eine große vergoldete Truhe mit einzelnen, mit einem Schlüssel verschlossenen Fächern herbeischaffen ließ. Jedes Fach enthielt das Bildnis eines Propheten auf einem Stück Seide. Hishâm bin al-'Aṣ berichtet von diesem Treffen, beschreibt das Aussehen jedes einzelnen Propheten und erkennt das Porträt Muhammads wieder, das im letzten Fach steckt. Als er und sein Gefährte Heraklius fragen, woher er diese Truhe erhalten hat, antwortet dieser, sie komme von Adam, sei aus dem Westen (Couchant) zurückgebracht und dann von Dhû l-Qarnayn Daniel anvertraut worden (Bayhaqî 1985, Bd. 1, S. 384-390). Diese bei Hamidullah (1960) erwähnte Überlieferung wird von Vâlsan (1962-63) kommentiert.

36. Ibn al-Jawzî (1976), Bd. 2, S. 39-67. Vgl. auch Suyûtîi (1967), Bd. 1, S. 149-177; dieser geht vom Siegel des Prophetentums aus, vermischt die Charakteristika der einzelnen Körperteile mit den 
physischen und intellektuellen Fähigkeiten (dem Gehör, der Stimme, der Intelligenz, dem Gang, der sexuellen Potenz, dem Nichtvorhandensein eines Schattens oder der Absenz nächtlicher Samenergüsse) und schließt mit den Besonderheiten seines Urins und seiner Exkremente. Es folgen die Überlieferungen zu seiner körperlichen Erscheinung und seinen Tugenden (s. oben).

37. Vgl. Ibn Mâja (1972), țahâra, 15, Hadith Nr. 301. Dieselbe Aussage wird 'Imrân bin Ḥuṣayn zugeschrieben; vgl. Ibn Ḥanbal (o. J.), Bd. 4, S. 439.

38. Muslim (1332 h): faḍ̂a'il al-ṣahâaba 83, Bd. 7, S. 116 f.; Ibn Ḥanbal (o. J.), Bd. 6, S. 88, 150, 167, sowie Țabarî, M. (1984), Bd. 3, S. 12 f.

39. Kândihlawî (1968), Bd. 2, S. 590 - nach 'Abd al-Razzâq und Ba'awî.

40. Am Ende des Lebens des Propheten, während seiner Abschiedswallfahrt, scheint diese Praxis wohletabliert gewesen zu sein. In al-Abțah, auf dem Rückweg aus Minâ, ruft Bilâl zum Gebet, betritt das Zelt des Propheten und verlässt es wieder mit dem Behältnis, an dem der Prophet seine rituellen Waschungen vollzogen hat, und alle beeilen sich, davon ein wenig zu bekommen (Bukhârî 2015, De Chaakteristika (Manâqib) 23 (șifat al-nabî), Hadith Nr. 3566, V: 36 f.

41. Kândihlawî (1968), Bd.2, S. 581 f.; nach Bayhaqî und Abû Nu'aym (Hilyat al-awliyâ, Bd.1, S. 330). Siehe auch S. 583, den Fall von Safîna, des jungen Freigelassenen des Propheten, der das Blut des Propheten trinkt, das dieser ihm wegzuschütten aufgetragen hatte.

42. Kândihlawî (1968), Bd. 2, S. 581 f.; nach Ibn Ḥajar al-Haythamî (1967), Bd. 8, S. 270.

43. Vgl. in diesem Zusammenhang die von Samhûdi (1984), Bd.1, S.67-69 zitierten Überlieferungen.

44. Die sich von Tunis aus einschiffenden Meeresreisenden brachten Erde vom Grab des Muhriz bin Khalaf, des Schutzheiligen der Stadt mit. Sie kippten etwas davon ins Meer, um die Stürme zu besänftigen. Abû Hâmid al-‘Arnâhî, Tuhfat al-albâb, zitiert nach Idris (1959), S. 328.

45. Muslim (1329 h), faḍ̂̉il 164, Bd.7, S.102. Ibn Hanbal (o.J.), Bd.3, S.120. Eine andere Überlieferung verallgemeinert diesen Fall: »Die Propheten leben in ihren Gräbern, betend.« (Subkî, 1371 h, S. 179 f.)

46. Subkî (1371 h), S. 179-196 (nach Bayhaqî, der dieser Frage ein Pamphlet (juz) gewidmet hat). Fîrûzâbâdî (1966), S. 127-132. Ibn Ḥajar al-Haythamî (2002), S. 138-142. Auch Suyûṭ̂i hat dieser Frage eine kurze Abhandlung gewidmet, ausgehend von dem Pamphlet des Bayhaqî. Er kritisiert einige Behauptungen Subkîs (Suyûṭ̂i, 1352 h, Bd. 2, S. 139-155; ebenso Suyûṭ̂i, 1967, Bd. 3, S. 403406).

47. Ibn Ḥanbal (o. J.), Bd. 2, S. 527, und Abû Dâwûd (o. J.), manâsik 98 [Die Gräber besuchen], Bd. 2, S. 492, Nr. 2041. Unter anderem zitiert von Ibn Qayyim al-Jawziyya (1968), S. 18 f.

48. Ibn Hanbal (o. J.), Bd. 2, S. 315. Man kann 'ajam als »Kern« lesen, oder als »Basis« (aṣl) des Schwanzes (Lisân al-'Arab, Bd. 15, S. 285). Es handelt sich also um den unteren Teil des sacrums, das diese Benennung erhielt, weil es den Göttern bei Tieropfern dargebracht wurde. Zur Vorstellung eines »Kerns der Unsterblichkeit« vgl. Guénon 1987, S. 62-66.

49. Corbin (1960). Siehe zumal die Auswahl der Texte im zweiten Teil.

50. Ibn Ḥanbal (o. J.), Bd. 3, S. 2. Siehe auch Bukhârî (2001), anbiyâ 35, Nr. 3414, wo der Prophet seine Gefährten warnt, ihn über die anderen Propheten zu stellen, wie sie es zu tun pflegen. Er erklärt: »Ich werde der Erste sein, der erweckt wird « [Wortlaut in Muslim (1329) (deutsch), Bd. 2, S. 863], doch er präzisiert, dass er dann den sich am Thron festhaltenden Moses sehen und sich fragen wird, ob der Donnerschlag auf dem Sinai ihm erspart hat, vom Schall der Trompete niedergestreckt zu werden, oder ob er wohl vor ihm zu neuem Leben erweckt wurde.

51. Bukhârî (2015), S. 349 f., Nr. 3326: »Allāh erschuf Adam in einer Körpergröße von sechzig Ellenlängen [...] Es wird dann geschehen, dass jeder, der ins Paradies eingehen wird, die Gestalt von Adam einnimmt. Seit damals bis zur heutigen Zeit ist die Menschengestalt immer weniger geworden.«

52. Bukhârî (2001), Die Gebetswaschung (wuḍ̂̀') 3, Nr. 136. Muslim (1329 h), țahâra 34, Bd.1, S. $149-150$. 
53. Man wird nichtsdestoweniger bemerken, dass für ein umfassendes Begreifen der Person des Propheten die Heiligkeit seines Körpers und seine Fürsprache in dieser und der anderen Welt niemals voneinander getrennt sind. Dies kann man bei einem jüngeren Werk feststellen, in dem sich ein Großteil der hier zitierten Traditionen wie auch andere wiederfinden: Ibn 'Alawî alMâlikî al-Ḥasanî (1993). Um einer bestimmten Tendenz des zeitgenössischen modernen Islam entgegenzuwirken, schafft der Autor, der im Haram von Mekka lehrt, in diesem Werk ein vielgliedriges Korpus von Verweisen, das die vielfältigen Modalitäten der prophetischen Fürsprache, die Besonderheit der prophetischen Körper und die vom Propheten selbst begünstigte Verehrung seines Körpers zu seinen Lebzeiten belegt (vgl. insbesondere S. 213-230). 54. Die Beziehung zwischen der Offenbarung und der Heiligkeit des Körpers wird besonders in der von al-Ḥasan al Bașrî überlieferten Tradition betont: »Den Körper dessen, zu dem der Heilige Geist (rû' al-quds) gesprochen hat, darf die Erde nicht mehr aufzehren.« (Suyûți 1967, Bd. 3, S. 403; nach al-Zubayr bin Bakkâr, Akhbâr al-Madîna).

55. Der Abstieg des Wortes in den Körper kann als Vollendung des Prozesses des Wiederaufstiegs des Geistes zu Gott durch die Rezitation und Erhöhung seines Wortes verstanden werden; das ist die Definition des Kampfes auf dem Weg zu Gott. Das erklärt, warum die im Kampf gefallenen Märtyrer, Zeugen des Wortes und genau eine Stufe unter der des Prophetentums stehend, Gott, der sie fragt, was sie sich im Paradies am meisten wünschen, antworten: „Wir bitten dich, unseren Geist in unsere irdischen Körper zurückzusenden, damit wir auf Deinem Weg getötet werden.« (Ibn Mâja 1972, jihâd 16, Nr. 2801).

INDEX

Mots-clés : corps, prophète, islam, hadith

Schlüsselwörter : Körper, Prophet, Islam, Hadith

\section{AUTEURS}

DENIS GRIL

Denis Gril ist emeritierter Professor an der Universität Aix-Marseille. Nähere Informationen finden Sie hier. 